\title{
Discrete simulations modelling the impact of operator numbers and truck availability on haulage fleet productivity
}

\author{
KJ Shelswell Labrecque Technologies Inc., Canada \\ PO Labrecque Labrecque Technologies Inc., Canada
}

\begin{abstract}
A discrete simulation was used to assess the impact of the number of haulage operators on the performance of truck haulage fleets. A dynamic simulation model was designed to quantify the productivity of an underground mine using diesel haulage trucks as prime movers in an operation with a single decline access. Truck haulage was simulated from load-haul-dump-serviced loadouts along the ramp and decline system to stockpile dump points on surface. The model was used to generate haulage productivity curves based on fleet size, operator crew size, and truck availability. These curves represent benchmark estimates for truck haulage operations to optimise crew planning based on historical and projected truck utilisation data.
\end{abstract}

Keywords: discrete event simulation, haulage productivity, truck utilisation, operator numbers

\section{Introduction}

Mobile material handling systems such as haulage trucks present an ideal opportunity for a number of mining operations because of their inherent flexibility. Trucks are available in a range of size, capacity, and dump method configurations to accommodate various mine designs such that truck specifications can be matched with headings and allow the development to be used to access and extract minerals from the deposit to also serve as the infrastructure used to transfer the material to stockpiles for rehandling or processing. Additional options such as engine type or modifications like sideboards can also be applied to customising the fleet to unique operating practices.

The key strength of truck haulage, however, can be attributed primarily to the ability to adapt haulage routes accordingly in response to current operations, future mining processes, and expansions or changes in mine plans as the life-of-mine progresses. This flexibility can prove to be beneficial as mineral extraction becomes more challenging in mine designs with resources segregated into numerous dispersed work areas, at greater depths, under high rock stress (Gentry 1976), or accessing smaller deposits (Moser 1996) that may not warrant the installation of fixed oreflow infrastructures such as rail lines (Bise 2003), conveyors (Yardley \& Stace 2008), and shafts (Edwards 1992).

One of the key limitations of truck haulage, however, is the wear and tear of operating conditions on equipment. Truck downtime can be impacted by a number of factors such as fleet age, muck fragmentation and truck payloads, truck loading practices, roadway conditions, ventilation and cooling, haulage distance, productivity targets, maintenance regimes, and mine design (Atkinson 1992). Because of this, it is important to maximise truck availability with respect to the underground conditions of each operation. This requires logistical applications for not only the equipment itself, but also the prime mover workforce; the truck operators. Too few operators can result in non-productive idle time on available trucks, while too many operators can generate unnecessary cost overruns and a decrease in workforce productivity. 
Dynamic models generate an assessment of the system as a whole by incorporating randomness to simulate the impact of discrete interactions between individual components of the operation on the entire process. Analysis was carried out to predict truck haulage fleet productivity while accounting for operator and equipment availability when emulating the movement of material from underground to stockpiles on surface. Results were interpreted to generate haulage estimates based on the truck utilisation to create benchmark productivity curves associated with haulage operator availabilities.

\section{$2 \quad$ Methodology}

\subsection{Model boundaries}

The upstream boundary used for the study was the production of ore from stopes and the generation of waste from lateral development. It was assumed that mining activities were able to efficiently generate sufficient tonnes to meet the production and development targets for the simulation. The downstream boundary of the simulation was the dumping of material at the run-of-mine (ROM) pad and waste stockpile site on surface. ROM and stockpile rehandling was considered to be unconstrained and was not included in the simulation.

\subsection{Mine design}

The model was designed to simulate an underground haulage operation with a 2,100 $\mathrm{m}$ long $5 \%$ grade decline access (Shelswell \& Labrecque 2014) to a single spiral ramp system. The ramp was $1,800 \mathrm{~m}$ long at a grade between 8 and 13\% with seven primary mine levels. Sublevels were not included in the simulation. The distance between each mine level on the ramp was $300 \mathrm{~m}$. Each level was designed with two separate loadouts - one for ore and one for waste - along the access drift from the ramp. Ore loadouts were located $40 \mathrm{~m}$ off the ramp while waste loadouts were $55 \mathrm{~m}$ from the ramp. Single truck air doors were incorporated $20 \mathrm{~m}$ down the level access drift coming off the ramp to control ventilation. The ROM pad on surface was located $300 \mathrm{~m}$ from the portal while the waste stockpile dump site was $440 \mathrm{~m}$ from the portal. The maintenance shop and fuel depot were both located on surface at distances of 260 and $270 \mathrm{~m}$ from the portal, respectively (Figure 1).

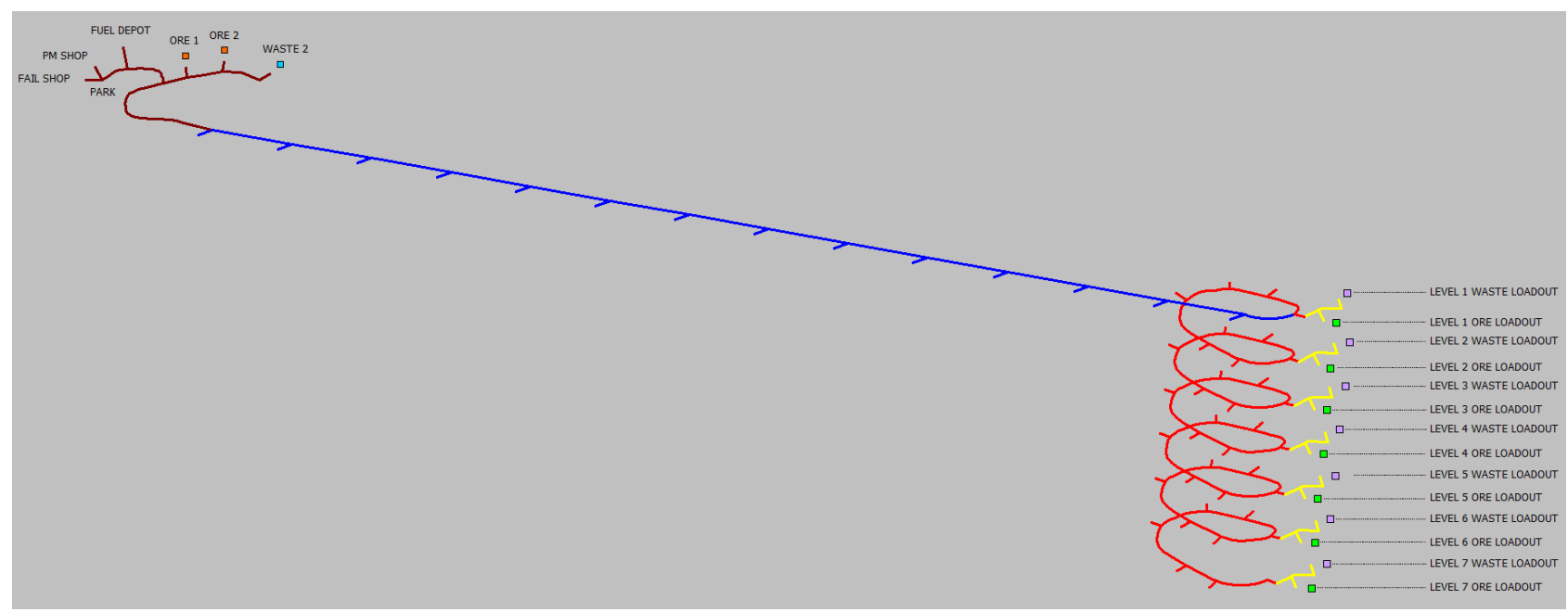

Figure 1 Mine layout: (brown line) surface roadway; (blue line) decline roadway; (red line) ramp roadway; (yellow line) level roadway; (orange square) surface ore tip site; (blue square) surface waste tip site; (purple square) underground waste loadout; (green square) underground ore loadout 


\subsection{Production and development scheduling}

The production and development schedule represented the mine targets for one calendar year (365 days) with a 5.5:1 ratio of ore to waste representative of a stope-based mining operation. Eleven non-production days representing statutory holidays, maintenance events, and random shutdowns were included where all haulage and underground activities were suspended. Scheduling was broken down by mine level with all production and development tonnes scheduled to ore and waste muck bays servicing truck loadouts. Ore and waste tonnes were scheduled daily based on symmetric triangular distributions (Forbes et al. 2011) to account for daily variability in the productivity of the mining operations. Triangular distributions are continuous probability distributions with a lower limit, upper limit, and peak value in the shape of a triangle (lower limit $\leq$ peak value $\leq$ upper limit) where the area under the curve is one. The probability of a value is defined by the height of that point on the curve. Ore tonnes were scheduled using a distribution of $\pm 35 \%$ while waste tonnes had a limit of $\pm 60 \%$. Tonnes were scheduled additively such that new daily calls of ore and waste were added to any previously scheduled tonnes not yet moved by the haulage trucks.

\section{$2.4 \quad$ Shift schedules}

Haulage and maintenance activities were modelled as schedule-based resources such that each haulage truck, loadout load-haul-dump unit (LHD), or maintenance personnel could only carry out one process at a time (Karnon et al. 2012). These activities were limited to the available hours defined by the appropriate daily shift schedules. Separate schedules were defined for haulage (trucks), underground operations (loadout LHDs), and surface activities (shop maintenance).

Shift availability was modelled based on a two-shift day for both surface and underground activities. Shift profiles included an off-shift component to create a $10.5 \mathrm{hr}$ shift duration during which the model could operate. Considerations were included in the shift profiles for pre-shift and post-shift factors like safety meetings, line-ups, travel, equipment checks, blasts, and ventilation clearances. These factors further reduced the availability of the on-shift profile to define a workable 'seat time' period during which processes could occur. Industry benchmarking was used to generate haulage, underground, and surface shift profiles with 54.17, 58.33, and 79.17\% on-shift workable availabilities (percent of the $12 \mathrm{hr}$ shift available for work), respectively.

\subsection{Haulage trucks}

The haulage fleet was modelled as manually operated diesel trucks. Inputs were generated based on benchmarking data collected from industry operations utilising 30 tonne payload trucks. Trucks were dispatched to underground loadouts based on simulated daily mining activities to haul production ore and development waste to stockpile tip sites on surface. The simulation included logic to incorporate the impact of equipment interactions, resource competition, and random variability in the haulage process on truck productivity. Resource competition pertained to the availability of modelled components with a fixed capacity such as pass bays (traffic), loadouts and dump sites (queuing), loadout LHDs (load delays), and maintenance (shop bays and fuel depot pumps). Random variability was captured by applying distributions to the input values defining simulated processes such as loading, dumping, and maintenance, and to the occurrence of truck breakdowns. The approaches used to simulate the haulage processes included in the model are described in the following sections. Inputs used for haulage truck and LHD operations are summarised in Table 1. Payloads represented average values, with LHDs paired to trucks to model two LHD buckets per truck payload. Any spillage clean-up or loadout maintenance processes not specifically modelled were accounted for in the LHD acquisition delay. 
Table 1 Model inputs used for haulage truck operations

\begin{tabular}{lll}
\hline Input specifications & Truck inputs & LHD inputs \\
\hline Payload - ore & 26.1 tonnes & 14.0 tonnes \\
Payload - waste & 24.6 tonnes & 12.5 tonnes \\
Load spot - duration & 0.82 minutes & 0.46 minutes \\
Load ore - duration & 6.69 minutes & 0.88 minutes \\
Load waste - duration & 6.69 minutes & 0.88 minutes \\
Dump spot - duration & 0.57 minutes & 0.55 minutes \\
Dump - duration & 0.88 minutes & 0.73 minutes \\
Speed - surface - loaded & $13.4 \mathrm{kph}$ & - \\
Speed - surface - empty & $17.4 \mathrm{kph}$ & - \\
Speed - decline - loaded & $11.2 \mathrm{kph}$ & - \\
Speed - decline - empty & $15.1 \mathrm{kph}$ & - \\
Speed - ramp - loaded & $9.2 \mathrm{kph}$ & - \\
Speed - ramp - empty & $12.9 \mathrm{kph}$ & - \\
Speed - level - loaded & $6.6 \mathrm{kph}$ & $5.89 \mathrm{kph}$ \\
Speed - level - empty & $7.6 \mathrm{kph}$ & $6.78 \mathrm{kph}$ \\
Acquisition delay - maximum & - & 3.0 minutes \\
Remuck stockpile tram - distance & - & 35 metres \\
Scheduled maintenance-associated availability & $99.8-100 \%$ & - \\
Random failure-associated availability & $30.2-95 \%$ & - \\
\hline
\end{tabular}

\subsubsection{Truck dispatch}

Trucks were dispatched from surface to haul ore or waste from loadouts on the mine levels underground. The dispatch algorithm considered muck type, mine productivity, and truck fleet distribution in an attempt to minimise haulage congestion. The payload type was determined by the ratio of ore tonnes versus the ratio of waste tonnes in the production and development plan, such that trucks were five and a half times more likely to be dispatched to haul ore than waste. Once a payload was selected, trucks were dispatched to the loadout with the highest amount of 'unclaimed' tonnes of that payload type remaining. The model did not limit the number of operating loadout LHDs, with an active LHD provided on each level with tonnes scheduled for haulage. Unclaimed tonnes were calculated by accounting for the number of trucks already currently dispatched to each location and subtracting these tonnes from the total at the loadout. If there was no suitable loadout for dispatch, the truck remained idle on surface.

Trucks required an operator to be dispatched for haulage. If a truck already had an operator, it could be dispatched for haulage. A truck could also be dispatched if it required an operator and drivers were available. Conversely, trucks without operators could not be dispatched and would remain idle if there were no free drivers. Active trucks released operators when going to the shop for planned maintenance and random failure repairs, or if the truck was not dispatched and went idle. Trucks retained their operators when refuelling. 


\subsubsection{Truck loading}

Trucks were filled underground at loadout locations along the access drift from the ramp to the mine levels. Loadouts were modelled as raised tip points to allow LHDs to side load trucks. Ore and waste were loaded at separate loadouts on each level. Trucks travelled along the level access drift to reach the loadout. If the load point was occupied, trucks would queue until access to the loadout was available. Trucks spotted into the available loadout before requisitioning an LHD. A triangular distribution with a $\pm 25 \%$ variability was used to represent spotting by reversing into the load position. Each level was equipped with one LHD for loading both ore and waste, so only one truck could be loaded at a time per level. A uniform distribution (Forbes et al. 2011) was used to simulate the delay associated with acquiring the LHD from rehandling or loading activities on the level. Once the LHD arrived at the loadout, a delay based on a triangular distribution with a $\pm 20 \%$ variability was used to simulate LHD spotting, loading, tramming, and dumping processes associated with rehandling muck between the remuck stockpile and the loadout. Truck payloads were determined by applying a triangular distribution with a $\pm 10 \%$ variability to the average payload inputs for the associated muck type. Loaded trucks released the LHD and departed the loadout to travel to surface.

\subsubsection{Truck dumping}

Both ore and waste dump areas for trucks were located on surface. The ROM pad was designed with two tip sites, whereas the waste stockpile only had one. Only one truck was allowed to dump per tip site at a given time. If all sites were occupied, trucks queued at the entrance until a tip site became available. Trucks that acquired a site spotted at the tip site, dumped their payload, and departed the area. Variability in the haulage dumping was achieved by using triangular distributions (Forbes et al. 2011) that included a $\pm 20 \%$ variability in the spot process and a $\pm 10 \%$ variability in the dumping process. Trucks departing the dump travelled back to the portal before being dispatched for another haulage cycle.

\subsubsection{Truck traffic}

Traffic interactions between haulage trucks were explicitly modelled during all underground movement. The decline was broken up into sections between pass bays while the ramp was broken up into sections between pass bays or levels. The level access drifts were broken up into segments between loadouts. Movement along any decline, ramp, or level segment was restricted to one direction at any time, and passing was limited to pull-outs at pass bays, levels, and loadouts. Traffic priority was given to loaded trucks travelling to surface. It was assumed that surface routes were wide enough to allow two-way travel, so traffic was not modelled along surface roadways.

\subsubsection{Truck availability}

Truck availability was modelled to include downtime associated with planned maintenance regimes, random equipment failures, and refuelling. All maintenance was carried out on surface at the shop location. The shop maintenance was modelled as a resource with the capacity to work on five trucks at a time and the fuel depot was programmed with two pumps. LHD availability was not modelled under the assumption that equipment was re-tasked as needed to load trucks in the event of LHD maintenance or breakdowns.

Planned maintenance (PM) and random failures were scheduled based on discretely modelled variables (Robinson 2004) tracking truck utilisation. Planned maintenance was modelled as a recurring interval derived from industry maintenance routines with an average service delay taken for each truck. A distribution of $\pm 20 \%$ was applied to the planned maintenance service delay. Random failures were modelled using a triangular distribution (Forbes et al. 2011) sampling a min/mode/max function (Onyango \& Plews 1987) generated from mean time between failure (MTBF) and mean time to repair (MTTR) benchmarking data from industry. A uniform distribution was used to initiate truck refuelling such that the fleet staggered refuelling activity throughout the shift. Trucks were only routed to refuel if a pump was available to avoid queuing at the depot. An average delay with a distribution of $\pm 10 \%$ was used to model the duration of each refuel event. 


\section{$3 \quad$ Results}

\subsection{Haulage truck dispatching}

The strength of a discrete event simulation lies in the ability to model the dynamic interactions between components of the system driven by resource availability (Karnon et al. 2012). The resources tracked in the model included trucks, haulage operators, truck loadouts, loadout LHDs, underground roadways (segments between pass bays on the decline, ramp, and levels), dump sites, fuel depot pumps, and maintenance shop bays. While the analysis was performed with a focus on truck and haulage operator availability, the dynamic interactions between mobile equipment and resources were tracked to validate the performance of the model.

The schedule was adjusted to conform to the truck fleet such that the number of active workplaces reflected the size of the truck fleet. Runs were performed with one active level for every two haulage trucks, and active levels were centred in the seven levels available on the ramp. This allowed the dispatch algorithm to retain a consistent potential for resource competition at the truck loadouts, while maintaining a similar average haul distance for all simulation scenarios. The cycle times (ore and waste trips) and loadout queue times for each fleet composition were compared to determine if the dispatch logic effectively distributed haulage dispatches throughout the system (Table 2). The haulage cycle time was measured as the time duration between arriving at a loadout, with an average cycle time for all fleet compositions of 44.27 minutes (with a maximum variation of $-1.5 \%$ and $+1.4 \%$ ). The loadout queue delays were tracked as a percentage of calendar time that trucks waited to spot at a busy loadout, with an average delay of $0.02 \%$, which translated to a total duration of approximately 13.5 minutes per shift. Cycle time and loadout queue statistics show that the various truck fleet scenarios maintained a similar haulage profile and that the dispatch logic was able to minimise loadout congestion by optimising the distribution of trucks during dispatching.

Table 2 Model inputs used for haulage truck operations

\begin{tabular}{lllll}
\hline Number of trucks & Active levels & Average cycle & Average loadout queue & Traffic delays \\
\hline 3 trucks & 2 & 44.89 minutes & $0.03 \%$ & $0-0.63 \%$ \\
4 trucks & 2 & 44.56 minutes & $0.02 \%$ & $0-0.94 \%$ \\
5 trucks & 3 & 44.20 minutes & $0.02 \%$ & $0-1.24 \%$ \\
6 trucks & 3 & 44.45 minutes & $0.01 \%$ & $0-1.56 \%$ \\
7 trucks & 4 & 44.57 minutes & $0.02 \%$ & $0-1.85 \%$ \\
8 trucks & 4 & 44.07 minutes & $0.02 \%$ & $0-2.11 \%$ \\
9 trucks & 5 & 43.61 minutes & $0.02 \%$ & $0-2.42 \%$ \\
10 trucks & 5 & 43.79 minutes & $0.01 \%$ & $0-2.72 \%$ \\
\hline
\end{tabular}

Benchmark data indicated that traffic delays higher than $8 \%$ (data not shown) were indicative of haulage bottlenecks due to decline and ramp congestion. Typical traffic in haulage operations includes both haulage trucks and support equipment such as drills, loaders, LHDs, personnel transporters and delivery vehicles like boom trucks or forklifts. However, the model was designed to not have truck haulage constrained by traffic so only the movement of haulage trucks was simulated and not the support equipment required to carry out mining activities. 
Traffic delays encountered along the decline, ramp, and levels increased in response to both truck and operator numbers up to $2.72 \%$ calendar time for 10 trucks (Table 2). This translated to a maximum of 19.56 minutes per shift and was well below the bottleneck threshold of $8 \%$. Results indicated that traffic modelled between haulage trucks increased by an average of $0.3 \%$ (equivalent to 2.16 minutes per shift) for each truck introduced to the fleet, given that operators were available to drive the trucks.

\subsection{Haulage truck productivity without operator constraints}

The impact of equipment availability on haulage productivity is the primary focus of many truck haulage studies. The initial approach to quantifying the impact of haulage truck availability was to assess the impact of fleet size without any haulage operator constraints. This was achieved by simulating all scenarios under conditions with as many operators as trucks. Truck availability was calculated based on two mechanical availability criteria; (a) planned maintenance-associated availability (Equation 1), and (b) random-failure-associated availability (Equation 2).

$$
\begin{gathered}
\left(\text { Freq }_{\mathrm{PM}}\right) /\left[\left(\text { Freq }_{\mathrm{PM}}\right)+\left(\text { Dur }_{\mathrm{PM}}\right)\right] \times\left(\text { Freq }_{\mathrm{FUEL}}\right) /\left[\left(\text { Freq }_{\mathrm{FUEL}}\right)+\left(\text { Dur }_{\mathrm{FUEL}}\right)\right] \\
\left(\mathrm{AVG}_{\mathrm{MTBF}}\right) /\left[\left(\mathrm{AVG}_{\mathrm{MTBF}}\right)+\left(\mathrm{AVG}_{\mathrm{MTTR}}\right)\right]
\end{gathered}
$$

where:

$$
\begin{array}{lll}
\text { Freq }_{\mathrm{PM}}= & \text { the frequency of planned maintenance in hours. } \\
\text { Dur }_{\mathrm{PM}}= & \text { the duration of the planned maintenance. } \\
\text { Freq }_{\mathrm{FUEL}}= & \text { the frequency of refuelling. } \\
\text { Dur }_{\mathrm{FUEL}}= & \text { the duration of refuelling. } \\
\text { AVG }_{\text {MTBF }}= & \text { the average mean time between failure. } \\
\mathrm{AVG}_{\text {MTTR }}= & \text { the average mean time to repair. }
\end{array}
$$

All values were represented in hours to generate a percent availability.

Availability was calculated by factoring the amount of operating time by the sum of the operating time and downtime related to maintenance. The two mechanical availability criteria were used to determine the overall mechanical availability by multiplying both factors to limit the amount of time trucks could operate during the on-shift period (operating/seat time) of the shift profile to determine the effective availability of the trucks.

The logic used for dispatching and resource competition in the model resulted in a linear relationship between haulage productivity and truck fleet size when normalised against the maximum productivity of 10 trucks operating at $100 \%$ overall mechanical availability with 10 haulage operators. The effect of maintenance and resource competition was then plotted for six different overall mechanical availability bracket; 50, 60, 70, 80, 90, and 100\% (Figure 2). 


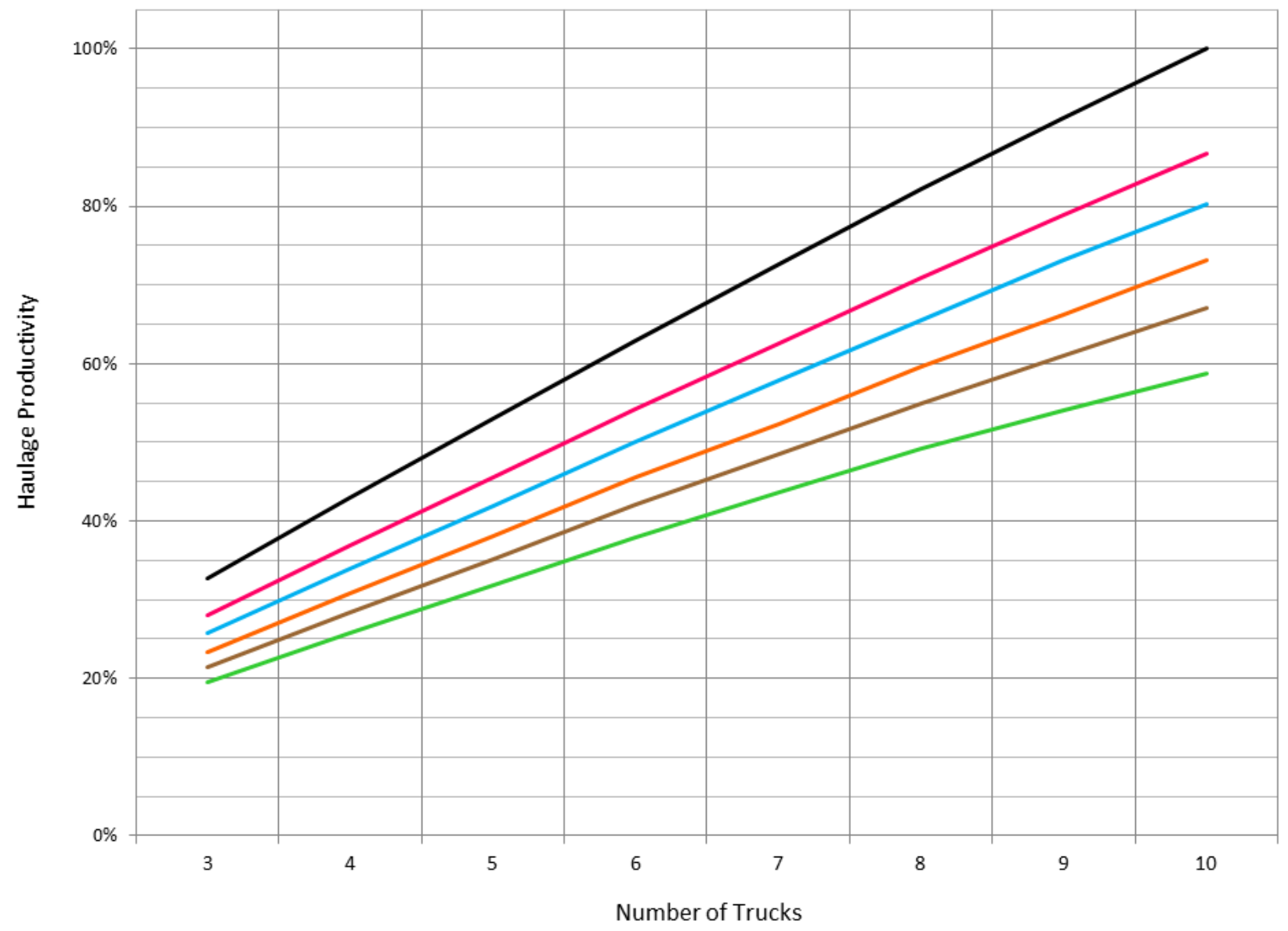

Figure 2 Haulage productivity analysis without haulage operator constraints. Average daily haulage rates from fleets with different overall availability were normalised against the productivity of 10 trucks operating at 100\% overall availability: (green line) 50\% availability; (brown line) $60 \%$ availability; (orange line) $70 \%$ availability; (blue line) $80 \%$ availability; (pink line) $90 \%$ availability; (black line) $100 \%$ availability

Given the assumption that personnel will always be present to operate trucks whenever they are available, the analysis provides an initial benchmark to predict haulage productivity based on expected fleet composition, truck payload, projected haulage cycle times, shift profiles, and expected overall mechanical availability of trucks. Determining the maximum haulage potential (100\% overall mechanical availability) of a fleet can be used to extrapolate a first-pass estimate of productivity from trucks based on the expected equipment availability on site. For example, given a truck availability of $80 \%$, the reference curve data can be used to extrapolate a requirement for eight trucks (two additional trucks) to meet the productivity of a six truck haulage fleet operating at $100 \%$ availability. Similarly, a fleet operating at $60 \%$ availability would require 10 trucks to meet the productivity of a six truck fleet operating at $100 \%$ (Figure 2).

\subsection{Haulage truck productivity with operator constraints}

The secondary consideration of the model was designed to quantify the effect of operator numbers on haulage productivity in conjunction with overall mechanical availability of the truck fleet. This was done by simulating all scenarios with a finite number of haulage operators ranging from one to 10 , which compounded the effective availability (overall mechanical availability and operating time) by operator availability.

Truck haulage was simulated for the six overall mechanical availability brackets described in Section 3.2, and daily haulage productivity was normalised against the maximum productivity (10 trucks with 10 operators) for each availability bracket. The impact of haulage operator availability followed a linear relationship with fleet size until the point of diminishing return (Hirschey 2009) as the curves reached an 
asymptote that represented the maximum productivity for the haulage fleet under each particular overall mechanical availability scenario. Because data was normalised to the maximum productivity of each availability bracket, the potential loss in productivity associated with adding another operator was characterised by a deviation of the curve from the 10 truck baseline (Figures 3 to 8 ).

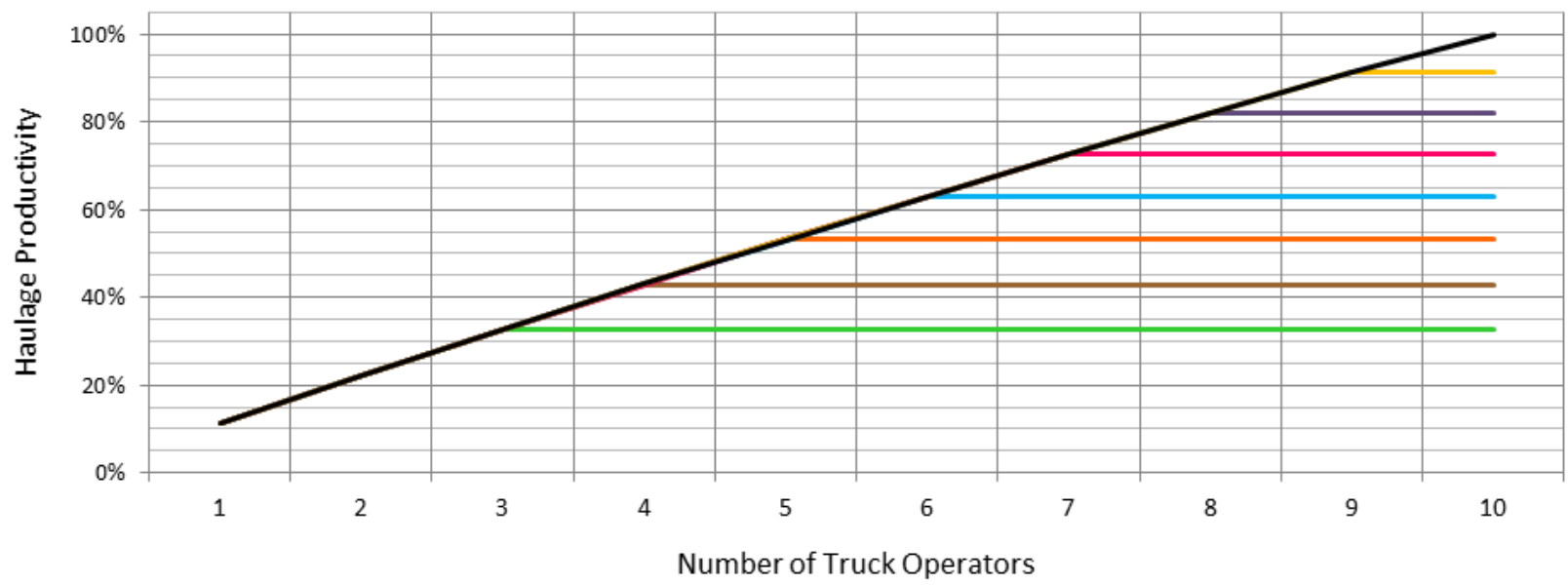

Figure 3 Haulage fleet size productivity analysis with haulage operator constraints and $100 \%$ overall mechanical availability. Average daily haulage rates were normalised against the productivity of 10 trucks operating at $100 \%$ overall availability with 10 operators: (green line) three trucks; (brown line) four trucks; (orange line) five trucks; (blue line) six trucks; (pink line) seven trucks; (purple line) eight trucks; (yellow line) nine trucks; (black line) 10 trucks

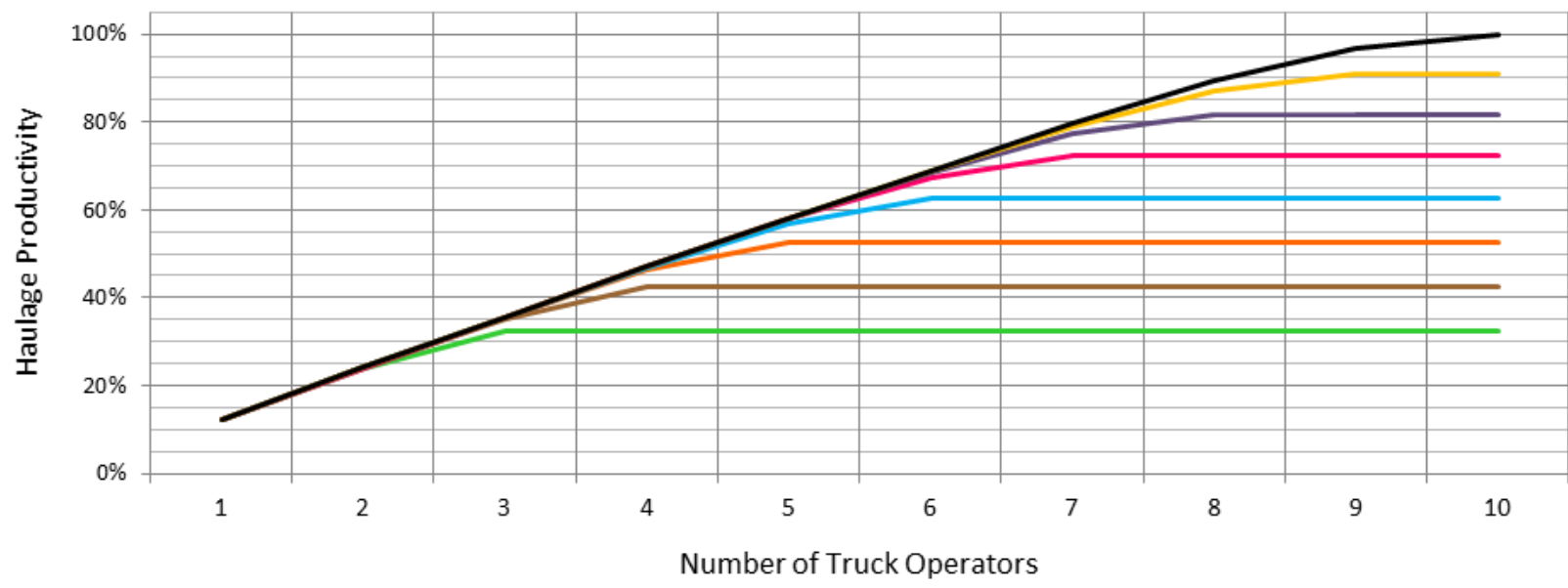

Figure 4 Haulage fleet size productivity analysis with haulage operator constraints and $90 \%$ overall mechanical availability. Average daily haulage rates were normalised against the productivity of 10 trucks operating at $90 \%$ overall availability with 10 operators: (green line) three trucks; (brown line) four trucks; (orange line) five trucks; (blue line) six trucks; (pink line) seven trucks; (purple line) eight trucks; (yellow line) nine trucks; (black line) 10 trucks 


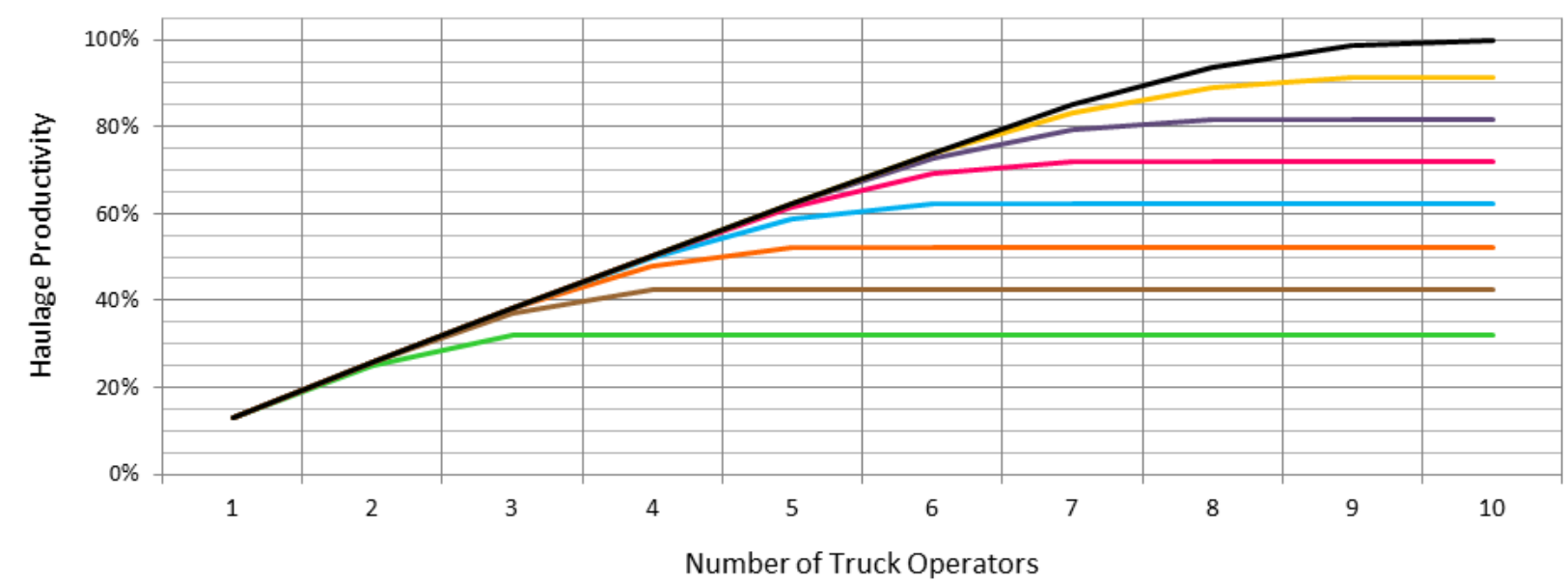

Figure 5 Haulage fleet size productivity analysis with haulage operator constraints and $80 \%$ overall mechanical availability. Average daily haulage rates were normalised against the productivity of ten trucks operating at $80 \%$ overall availability with 10 operators: (green line) three trucks; (brown line) four trucks; (orange line) five trucks; (blue line) six trucks; (pink line) seven trucks; (purple line) eight trucks; (yellow line) nine trucks; (black line) 10 trucks

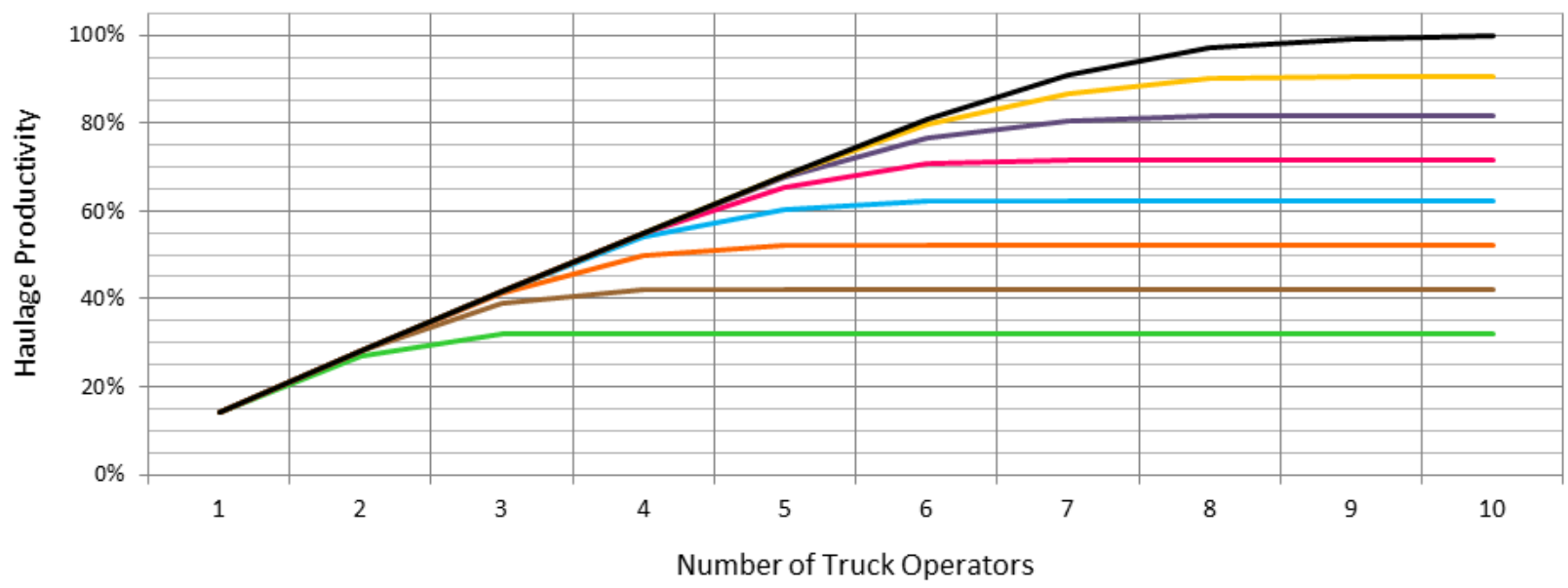

Figure 6 Haulage fleet size productivity analysis with haulage operator constraints and $70 \%$ overall mechanical availability. Average daily haulage rates were normalised against the productivity of 10 trucks operating at $70 \%$ overall availability with 10 operators: (green line) three trucks; (brown line) four trucks; (orange line) five trucks; (blue line) six trucks; (pink line) seven trucks; (purple line) eight trucks; (yellow line) nine trucks; (black line) 10 trucks 


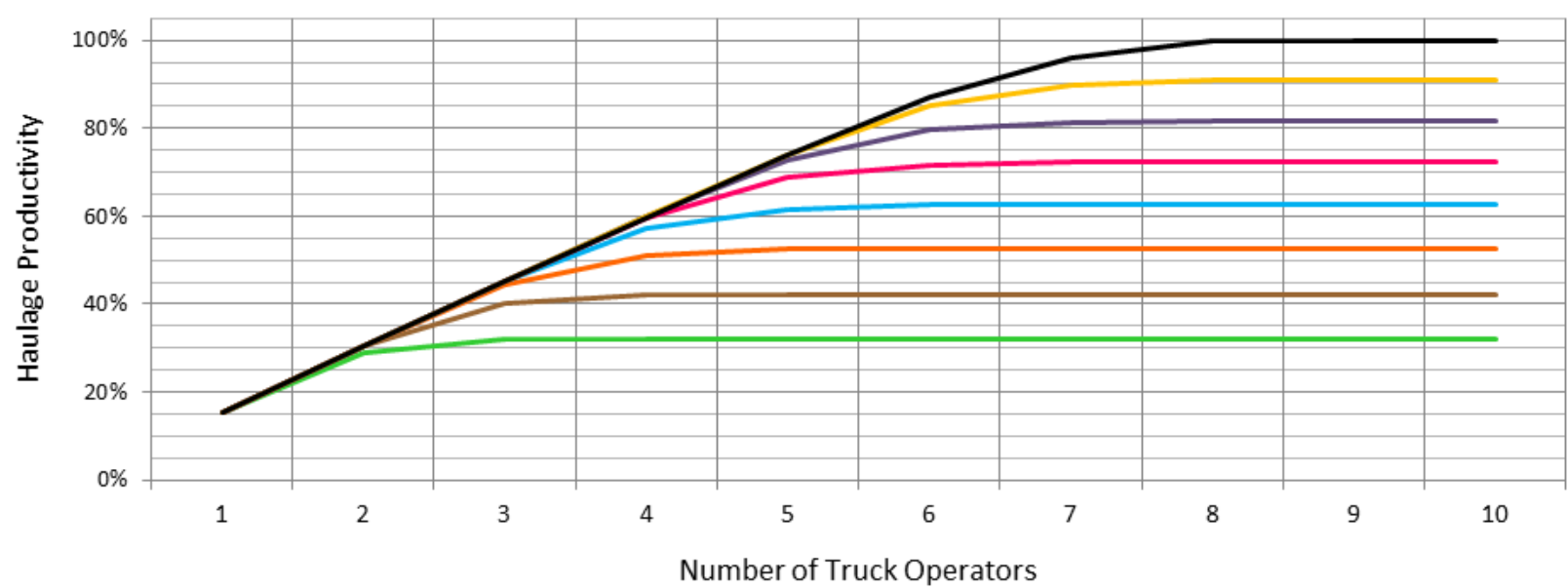

Figure 7 Haulage fleet size productivity analysis with haulage operator constraints and $60 \%$ overall mechanical availability. Average daily haulage rates were normalised against the productivity of 10 trucks operating at $60 \%$ overall availability with 10 operators: (green line) three trucks; (brown line) four trucks; (orange line) five trucks; (blue line) six trucks; (pink line) seven trucks; (purple line) eight trucks; (yellow line) nine trucks; (black line) 10 trucks

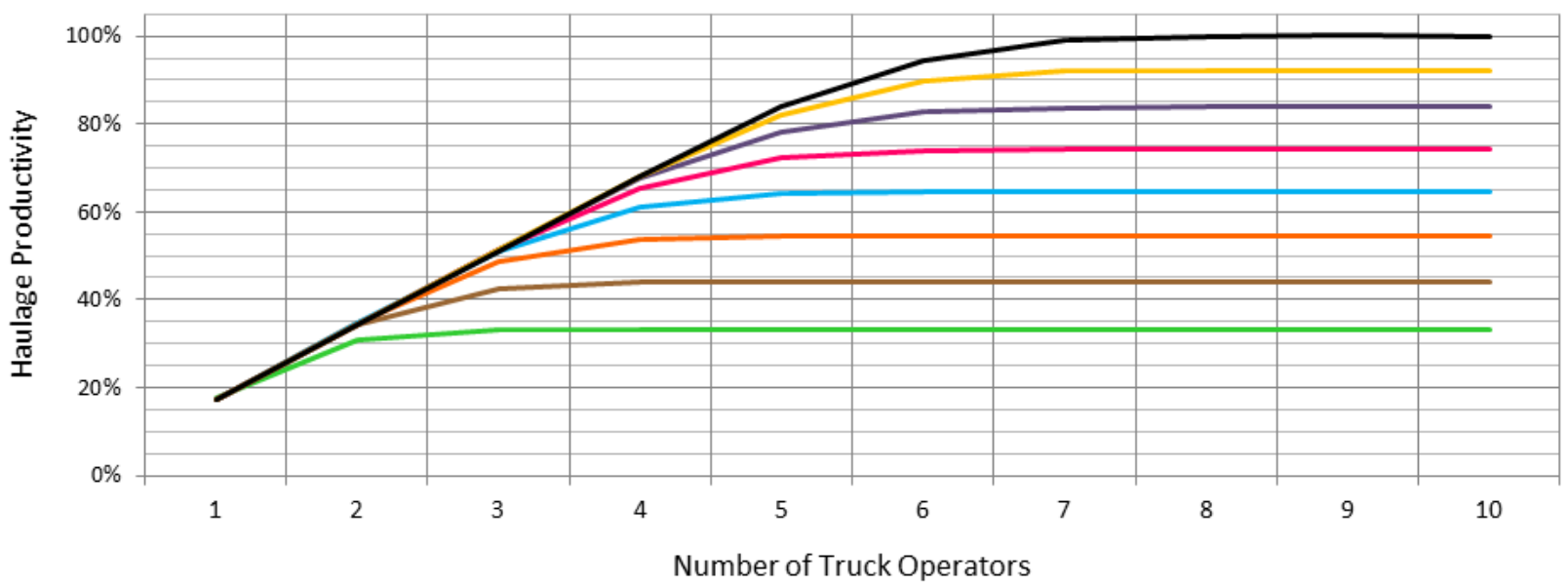

Figure 8 Haulage fleet size productivity analysis with haulage operator constraints and $50 \%$ overall mechanical availability. Average daily haulage rates were normalised against the productivity of 10 trucks operating at $50 \%$ overall availability with 10 operators: (green line) three trucks; (brown line) four trucks; (orange line) five trucks; (blue line) six trucks; (pink line) seven trucks; (purple line) eight trucks; (yellow line) nine trucks; (black line) 10 trucks

The effectiveness of additional haulage operator availability decreased in a direct relationship with overall mechanical availability on the trucks (compare Figure 3 with Figure 4). The productivity curves generated by the analysis represent a quantitative measure (represented as percent productivity increase) of added value from haulage operator staffing based on the expected overall mechanical availability of the truck fleet in a haulage operation. For example, if operating a four truck fleet with an availability of $50 \%$, the effectiveness of the crew size drops off after two operators. Staffing a third and fourth operator generated diminishing productivity returns of 42.4 and $43.9 \%$, respectively. When compared to a five truck fleet, this translated to $6.1 \%$ less productivity with three operators, and $9.8 \%$ less productivity with four operators (Figure 8). These curves can be used when factoring operational costs (such as fleet operations and crew staffing) with market values to predict the cost effectiveness of mine planning decisions. 


\section{Conclusion}

The simulation model was designed to quantify the impact of truck operation on mine haulage productivity. The model was used to define curves intended to be applied to truck and operator logistics decisions based on predicted site-specific truck utilisation conditions. Simulation analysis generated benchmark reference curves for haulage productivity in relation to both truck and operator availability. The one-dimensional analysis curve representing maximum haulage productivity predictions (Figure 2) provided value in fleet sizing studies, whereas the two-dimensional analysis curves representing haulage productivity based on both overall mechanical and haulage operator availabilities quantified the benefit from each operator as a percentage increase in haulage productivity (Figures 3 to 8 ).

\section{References}

Atkinson, T 1992, 'Selection and sizing of excavating equipment', in HL Hartman (ed.), SME Mining Engineering Handbook, Volume 2, 2nd edn, Society for Mining, Metallurgy, and Exploration, Littleton, pp. 1311-1333.

Bise, CJ 2003, Mining Engineering Analysis, Society for Mining, Metallurgy, and Exploration, Littleton.

Edwards, FA 1992, 'Hoisting systems', in HL Hartman (ed.), SME Mining Engineering Handbook, vol. 2, 2nd edn, Society for Mining, Metallurgy, and Exploration, Littleton, pp. 1646-1678.

Forbes, C, Evans, M, Hastings, N \& Peacock, B 2011, Statistical Distributions, John Wiley and Sons Inc., Hoboken.

Gentry, DW 1976, 'Development of deep mining techniques', in GJS Govett \& MH Govett (eds), World Mineral Supplies: Assessment and Perspective, Elsevier Scientific Publishing Company, Amsterdam, pp. 397-417.

Hirschey, M 2009, Managerial Economics, 12th edn, Cengage Learning, Mason.

Karnon, J, Stahl, J, Brennan, A, Caro, JJ, Mar, J \& Möller, J 2012, 'Modeling using discrete event simulation: a report of the ISPORSMDM Modeling Good Research Practices Task Force-4', Value In Health, vol. 15, no. 6, pp. 821-827.

Moser, P 1996, 'Primary development of underground hardrock mines', in WT Hennies, LA Ayres da Silva \& AP Chaves (eds), Mine Planning and Equipment Selection 1996, A.A. Balkema, Rotterdam, pp. 31-36.

Onyango, JP \& Plews, AM 1987, A Textbook of Basic Statistics, East African Educational Publishers Ltd., Nairobi.

Robinson, S 2004, Simulation: The Practice of Model Development and Use, John Wiley and Sons Ltd., West Sussex.

Shelswell, KJ \& Labrecque, PO 2014, 'Discrete simulations quantifying the effects of material handling conveyors in series or parallel oreflow streams', Proceedings of the 2014 SME Annual Meeting \& Exhibit, Society for Mining, Metallurgy and Exploration, Littleton, pp. 444-446.

Yardley, ED \& Stace, LR 2008, Belt Conveying of Minerals, Woodhead Publishing Limited, Cambridge. 